\title{
Response of Hydrological Drought to Meteorological Drought under the Influence of Large Reservoir
}

\author{
Jiefeng Wu, ${ }^{1}$ Xingwei Chen, ${ }^{1,2,3}$ Lu Gao, ${ }^{1,2,3}$ Huaxia Yao, ${ }^{4}$ Ying Chen, ${ }^{1,2,3}$ and Meibing Liu ${ }^{1,2,3}$ \\ ${ }^{1}$ College of Geographical Sciences, Fujian Normal University, Fuzhou 350007, China \\ ${ }^{2}$ Fujian Provincial Engineering Research Center for Monitoring and Assessing Terrestrial Disasters, Fujian Normal University, \\ Fuzhou 350007, China \\ ${ }^{3}$ State Key Laboratory of Subtropical Mountain Ecology (Funded by Ministry of Science and Technology and Fujian Province), \\ Fujian Normal University, Fuzhou 350007, China \\ ${ }^{4}$ Dorset Environmental Science Center, Ontario Ministry of Environment and Climate Change, 1026 Bellwood Acres Road, \\ Dorset, ON, Canada P0A 1E0
}

Correspondence should be addressed to Xingwei Chen; cxwchen215@fjnu.edu.cn

Received 16 May 2016; Revised 14 July 2016; Accepted 18 August 2016

Academic Editor: Shraddhanand Shukla

Copyright (C) 2016 Jiefeng Wu et al. This is an open access article distributed under the Creative Commons Attribution License, which permits unrestricted use, distribution, and reproduction in any medium, provided the original work is properly cited.

\begin{abstract}
Based on monthly streamflow and precipitation data from 1960 to 2010 in the Jinjiang River Basin of China, Standardized Precipitation Index (SPI) and Standardized Streamflow Index (SSI) were used to represent meteorological and hydrological drought, respectively. The response of hydrological drought to meteorological drought under the influence of Shanmei reservoir was investigated. The results indicate that SPI and SSI have a decreasing trend during recent several decades. Monthly scales of SSI series have a significant decreasing trend from November to the following February and a significant increasing trend from May to July at Shilong hydrological station. There are three significant periodic variations with a cycle of 6-7 years, 11-12 years, and 20-21 years for annual scales of SSI series. SPI series have the same periodic variations before the $1980 \mathrm{~s}$, but they have not been synchronous with SSI since the 1980s at Shilong due to influences of Shanmei reservoir, especially at the periodic variations of 20-21 years. The variation of the lag time of hydrological drought in response to meteorological drought is significant at the seasonal scale. The lag time of hydrological drought to meteorological drought extends one month on average in spring, summer, and autumn but about three months in winter.
\end{abstract}

\section{Introduction}

Global warming has increased the frequency and intensity of extreme climate events such as drought [1]. The global annual economic loss owing to the drought ranges from 6 to 8 billion dollars and is higher than other meteorological disasters [24]. China is one of the countries that experiences the most frequent droughts and the most severe damage. Overall, the evolution of drought in China has exhibited a correlation with global drought $[5,6]$.

Drought typically is categorized as meteorological drought, agricultural drought, hydrological drought, and socioeconomic drought $[7,8]$. Indices of meteorological drought are typically based on precipitation, and hydrological drought is based on streamflow. A meteorological drought may develop quickly, while a hydrological drought lags behind meteorological drought. The lag time depends upon watershed characteristics such as evapotranspiration capacity, the properties of the underlying surface (e.g., geology, soil, and vegetation conditions), and management factors (e.g., construction of reservoirs and dams) of the drainage basin $[9,10]$. In recent decades, the construction of large reservoirs has shown a significant impact on surface hydrological processes and runoff mechanisms, and it also can interfere with the natural evolution of hydrological drought in the drainage basins $[11,12]$. The evaluation of the response relationship between meteorological drought and hydrological drought impacted with large reservoirs is important for the realization of early warning and drought prevention as well as the mitigation of hydrological drought. 
A drought index is a measurement that reflects the cause and extent of drought. In principle, a good drought index should be well defined, physically meaningful, based on conveniently collected data, and computationally stable. The Standardized Precipitation Index (SPI) [13] can meet these analysis requirements under different water resource conditions $[13,14]$. Previous studies applying this method have been conducted in different regions (e.g., USA, China, Ethiopia, Korea, and Iran) [14-21] and confirmed that this method is of practical significance. Having similar characteristics as SPI, Standardized Streamflow Index (SSI) [22], which uses streamflow as the characteristic index and evolved from SPI, has been widely applied to the hydrological drought studies $[10,19,20]$.

Currently, two primary methods are used to investigate the response of hydrological drought to meteorological drought: the first is based on the simulation of hydrological models to investigate the relationship of the temporal-spatial dynamic changes of two types of drought $[19,20]$. Because the definition of large reservoir parameters is ambiguous in hydrological models, if the simulation results are not properly verified, large errors may occur in the response evaluation results $[19,20]$. The other method is the statistical analysis. Because the correlation analysis of the drought characteristics is based on measured hydrological and meteorological data, this method possesses high operability and has been widely applied [23-26]. Wen et al. [23] used long term streamflow data to analyze the Murrumbidgee River Basin in Australia and showed that the regulation of upstream reservoirs alleviates the extent of hydrological drought in the downstream irrigation regions. In a study of the Diyala River Basin in Central Asia, Al-Faraj and Scholz [24] showed that the construction of upstream reservoirs significantly changed the downstream hydrological conditions and exacerbated the extent of downstream hydrological drought. Furthermore, in an investigation of the change in the upstream and downstream hydrological conditions of a drainage basin, Huang et al. [25] and Zhang et al. [26] showed that the correlation between a hydrological drought and a meteorological drought is closely related to the construction of hydraulic projects. These studies focused on revealing how the construction of large reservoirs has changed the hydrological conditions and the variation of hydrological drought. However, the changes in response of hydrological drought to meteorological drought under the effect of large reservoirs remain to be further investigated.

Therefore, taking the Jinjiang River Basin in the southeastern coast of China and selecting the Shilong hydrological station which is affected by a large reservoir and Anxi hydrological station which is not affected by a reservoir, a comparative analysis was made to explore the differences in drought response in this study. Based on the monthly streamflow data from 1960 to 2010 and the corresponding precipitation data of three meteorological stations, the changes in response of hydrological drought (SSI) to meteorological drought (SPI) under the impact of large reservoirs (Shanmei Reservoir) in the drainage basin were investigated through a comparative analysis using the nonparametric Mann-Kendall test [27, 28], a wavelet analysis [29], and a Pearson correlation analysis.

\section{Overview of the Study Area}

Jinjiang River Basin is located in Quanzhou City, Fujian Province, which is the starting point of China's 21st century "Silk Road on the Sea." The drainage area is $5629 \mathrm{~km}^{2}$, the total river length is $302 \mathrm{~km}$, and the length of the mainstream is $182 \mathrm{~km}$. Jinjiang River Basin is the third largest river in Fujian Province. Dongxi and Xixi Rivers are tributaries in the drainage basin, and these two tributaries converge downstream at Shilong hydrological station. The drainage area controlled by Shilong hydrological station is $5024 \mathrm{~km}^{2}$ and accounts for $89.60 \%$ of the total Jinjiang River Basin. The drainage basin upstream of this hydrological station is selected as the study area (Figure 1). Climate in the drainage basin is characterized as South Asia humid subtropical monsoon climate with a mean annual rainfall of $1868 \mathrm{~mm}(1960$ 2010) and a mean temperature of around $20^{\circ} \mathrm{C}$. The area is characterized by significant monsoon climate, with clear wet and dry seasons [30]. Precipitation from March to September in the wet season accounts for $83.8 \%$ of total annual precipitation, while precipitation in the five months of the dry season, from October to February, accounts for only $16.20 \%$. This area is one of the poorest water resource areas in Fujian Province with annual mean surface water resources of 9.63 $\times 10^{9} \mathrm{~m}^{3}$, which is only $8 \%$ of the Fujian Province's average (http://www.fjwater.gov.cn/). This area frequently experiences hydrological droughts [31]. To meet the regional water usage requirement, several large and small reservoirs have been constructed, among which Shanmei Reservoir located in the middle tributary of Dongxi Basin has a water area of $1,023 \mathrm{~km}^{2}$ and a total storage capacity of $6.55 \times 10^{8} \mathrm{~m}^{3}$. The reservoir is with multiple-annual regulating functions such as irrigation, power generation, and water supply. It is the only large multifunction reservoir in Jinjiang River Basin. The dam filling was completed in 1972, while the protection and expansion were conducted in 1979. At the end of 1982, the construction of the reservoir was fully completed. In addition, when the Longmentan Water Diversion Project was completed in 1989, the drainage area upstream of the diversion dam was $360 \mathrm{~km}^{2}$, and the annual water diversion was $4.06 \times 10^{8} \mathrm{~m}^{3}$. Using a transbasin diversion, this project introduced or delivered the Dazhangxi mainstream streamflow of the Min River Basin to the lateral lake, Huyangxi, of Dongxi, which is a tributary of Jinjiang River Basin. The streamflow from Min River Basin then converged to the Shanmei Reservoir and was transported to the downstream Shilong hydrological station by regulation of the reservoir.

\section{Materials and Methods}

3.1. Materials. Hydrological and meteorological data were obtained from the Fujian Provincial Hydrology and Water Resources Survey Bureau and the Fujian Provincial Meteorological Bureau. The data included the monthly streamflow of two hydrological stations (Shilong and Anxi) between 1960 and 2010. Shilong station is located at the confluence of the Dongxi and Xixi tributaries. The streamflow was affected by Longmentan Water Diversion Project in the Dongxi tributary and the Shanmei Reservoir. Considering the relatively 


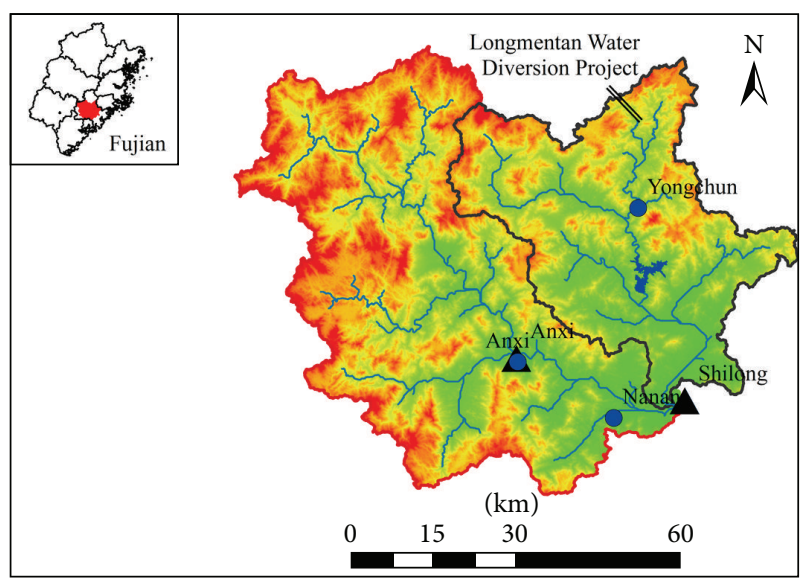

Meteorological station
Hydrological station
River
Shanmei Reservoir
Dongxi basin
Xixi basin
DEM/m
High: 1580
Low: 10

FIGURE 1: Location of the study area and hydrologic and meteorological stations.

small study area and the even distribution of meteorological stations, the monthly precipitation was obtained from the calculation of the arithmetic mean of the three meteorological stations (Nan'an, Anxi, and Yongchun) from 1960 to 2010. According to the four-season classification method in meteorology for China, March-May is the spring, JuneAugust is the summer, September-November is the autumn, and December-February is the winter.

\subsection{Methods}

3.2.1. Standardized Precipitation/Streamflow (SPI/SSI). Standardized Precipitation Index (SPI) is used to represent meteorological drought, while Standardized Streamflow Index (SSI) is for hydrological drought. The 51-year monthly precipitation and streamflow data from 1960 to 2010 were used to calculate SPI and SSI at different time scales. Therefore, the suitable probability distribution types for the variables were first determined, and then SPI and SSI were obtained after normal standardization. Calculated SPI and SSI can be used to monitor hydrological and meteorological drought characteristics under multiple temporal and spatial scales and thus provide a reliable method for obtaining the response patterns of hydrological drought to meteorological drought [16-20]. Shukla determined that compared to other probability density functions the streamflow series conforms more to a Log-Normal function [21]. Angelidis et al. [15] investigated and compared the fitting effect of Gamma, Normal, and Log-Normal functions on precipitation series
TABLE 1: Fitting theoretical probability distributions of Log-Normal functions for streamflow and precipitation at 1-, 3-, 6-, 12-month time scales with K-S test.

\begin{tabular}{lccccc}
\hline \multirow{2}{*}{ Time scales } & \multicolumn{2}{c}{ Hydrological station } & \multicolumn{3}{c}{ Meteorological station } \\
& Shilong & Anxi & Nan'an & Anxi & Yongchun \\
\hline 1-month & $\sqrt{ }$ & $\times$ & $\times$ & $\times$ & $\times$ \\
3-month & $\sqrt{ }$ & $\sqrt{ }$ & $\times$ & $\times$ & $\times$ \\
6-month & $\sqrt{ }$ & $\sqrt{ }$ & $\sqrt{ }$ & $\sqrt{ }$ & $\times$ \\
12-month & $\sqrt{ }$ & $\sqrt{ }$ & $\sqrt{ }$ & $\sqrt{ }$ & $\sqrt{ }$ \\
\hline
\end{tabular}

Note: $\sqrt{ }$ and $\times$ mean distribution acceptable for fitting data at confidence level $99 \%$ or not, respectively.

at different time scales. Their results showed that the LogNormal function had good applicability on the precipitation series at time scales greater than a month. In order to confirm the applicability of this conclusion in Jinjiang River Basin, the Kolmogorov-Smirnov (K-S) test method [32, 33] is performed to examine the goodness of fit of Log-Normal distribution for the precipitation and streamflow at 4 time scales (1-month, 3-month, 6-month, and 12-month), as listed in Table 1. The Log-Normal fits better at different time scales for streamflow overall and at longer time scales (6-month and 12-month) for precipitation, which is consistent with the conclusions previously obtained for the Xijiang River Basin (southeastern China) [20]. Therefore, Log-Normal function was selected as the probability distribution type for variables. The detailed calculation procedures can be referred to in previous studies $[15,18]$.

3.2.2. Mann-Kendall Algorithm. Mann-Kendall (M-K) nonparametric trend test method is recommended by the WMO (World Meteorological Organization), as a nonparametric approach for calculating the trends of hydrometeorological series $[27,28]$. M-K test was used to analyze the trend of SSI and SPI series in this study. The detailed calculation method is based on the test statistic $S$, which is expressed as follows [34]:

$$
S=\sum_{i<j} \operatorname{sgn}\left(x_{j}-x_{i}\right)
$$

where $x_{j}, x_{i}$ are series of data values, and the sign function is defined as

$$
\operatorname{sgn}\left(x_{j}-x_{i}\right)= \begin{cases}1 & x_{j}>x_{i} \\ 0 & x_{j}=x_{i} \\ -1 & x_{j}<x_{i}\end{cases}
$$

The variance of $S$ is calculated as follows:

$$
\operatorname{var}(S)=\frac{n(n-1)(2 n+5)}{18} .
$$

" $n$ " represents the length of data series. Mann and Kendall have suggested that when $n \geq 8$, the statistic $S$ is 
approximately normally distributed with zero mean $[27,28]$. Then, the standardized test statistic $Z$ is calculated by

$$
Z= \begin{cases}\frac{S-1}{\sqrt{\operatorname{var}(S)}} & S>0 \\ 0 & S=0 \\ \frac{S+1}{\sqrt{\operatorname{var}(S)}} & S<0 .\end{cases}
$$

The standardized M-K nonparametric statistic $Z$ follows the standard normal distribution with mean of zero and variance of one. If $|Z|>Z_{\alpha / 2}$, a significant trend is accepted to exist in the time series, where $Z_{\alpha / 2}$ is the $Z$ value of the standard normal distribution with an exceeding probability of $\alpha / 2$. The significance level $\alpha$ is set as 0.05 and 0.01 in this study, and their corresponding $Z$ value is 1.96 and 2.38 , respectively. When $2.380>Z>1.96$ it means a significant increasing trend and $Z>2.38$ means the increasing trend is extremely significant, while $-2.38<Z<-1.96$ and $Z<-2.38$ indicates a significant and extremely significant decreasing trend, respectively [34].

3.2.3. Continuous Wavelet Transform (CWT). Continuous wavelet transform (CWT) [29] is a useful mathematical method to study the information in time-frequency domains from the perspective of multi-time scales, which has been widely used to identify periodic oscillations of signals $[6,35]$. And the basis of a Morlet wavelet $(\Phi)$ is given as

$$
\Phi(t)=\pi^{-1 / 4} e^{i c t} e^{-t^{2} / 2},
$$

where $\Phi(t)$ is the Morlet wavelet function, $i$ is defined as imaginary symbol of a complex, $c$ is the dimensionless frequency, and $t$ is the dimensionless time parameter. Given a time series $X_{n}$ and $t=0,1, \ldots, n$, then the CWT can be computed by

$$
\begin{aligned}
\operatorname{var}(a) & =\int_{-\infty}^{\infty}\left\{W_{n}(a, b)\right\}^{2} d b, \\
W_{n}(a, b) & =|a|^{-1 / 2} \int_{-\infty}^{\infty} X_{n}(t) \phi^{*}\left(\frac{t-b}{a}\right) d t,
\end{aligned}
$$

where $\operatorname{var}(a)$ is wavelet variance; $W_{n}(a, b)$ is the wavelet transform coefficient, which can represent the characteristics of the signal change at different times scales; $a$ and $b$ are called a scaling parameter and a translation parameter, which measures the degree of compression or scale and determines the time location of the wavelet, respectively; and $\phi^{*}$ is the complex conjugate of $\phi$. In the derivation process of wavelet filtering, it is assumed that the signals are infinite; however, the signals that will be processed are finite in practical progress; therefore the border of composition signals will have great error, which is called "boundary effect" [36]. Thus when the CWT was used to eliminate the "boundary effect" on the two boundaries of the variable (i.e., the time series), symmetryextending was applied to the time series. According to analysis of the wavelet coefficients at time-frequency domains from the perspective of multi-time scales, we can obtain the differences of periodic components between two time series.
3.2.4. Pearson Correlation Coefficients (PCC). Pearson correlation coefficient (PCC) was used to quantitatively measure the correlation of SSI and SPI at different time scales to compare the evolution characteristics and the relationship between meteorological drought and hydrological drought. The PCC is defined as [37]

$$
\mathrm{PCC}=\frac{\sum_{i=1}^{n}\left(\varphi_{i}-\bar{\varphi}\right)\left(\rho_{i}-\bar{\rho}\right)}{\sqrt{\sum_{i=1}^{n}\left(\varphi_{i}-\bar{\varphi}\right)^{2}} \sqrt{\sum_{i=1}^{n}\left(\rho_{i}-\bar{\rho}\right)^{2}}},
$$

where $\varphi_{i}$ and $\rho_{i}$ represent the two time series of values, with $i=1, \ldots, n$. PCC values range from -1 to 0 indicates that sets are negatively correlated, while values from 0 to 1 mean they are positively correlated. In order to analyze how hydrological drought responds to meteorological drought, we used PCC method to analyze the time lag between hydrological drought and meteorological drought by using the monthly SSI (SSI1) series and SPI at different time scales (SPI-1 to SPI-12) for each month, by finding the differences between the drought durations. For example, SSI-1 and SPI-3 have higher PCC values; this indicates that the time response of hydrological drought to meteorological drought is about two months. The higher PCC suggests that this response time is more sensitive and vice versa [38].

\section{Analysis of Results}

\subsection{Response of Hydrological Drought to the Evolution of Meteorological Drought}

4.1.1. Response of Trend Change. The M-K trend test approach was utilized to analyze the trends of monthly SSI values and total series at Shilong, Anxi hydrological station, and SPI series in study area. The M-K statistic values of SSI and SPI in the total series on a monthly scale are all greater than zero (Table 2). Shilong station passed the 0.01 significance test, Anxi station passed the 0.05 significance test, and SPI total series passed the 0.05 -significant-level test. $\mathrm{M}-\mathrm{K}$ values of SSI and SPI exhibited a trend of pronounced increase, indicating that the Jinjiang River Basin did not exhibit a significant drought trend over 51 years. This conclusion is consistent with findings by Y. Chen and X.-W. Chen [39], who found a trend of general development towards flood in Fujian Province as observed in 1960-2006 using SPI. According to Yang et al. [40] and $\mathrm{Wu}$ [41], a rapid temperature increase occurred in Fujian in recent decades, combining with a remarkable increase in precipitation, which is more pronounced in the southeastern coast of Fujian. These results suggest a good consistency between the nonsignificant trends of droughts in the Jinjiang River Basin and warming-wetting climate in the southeastern coast of Fujian.

The results of monthly M-K trend test indicate that the SSI and SPI sequence values have statistically significant decreasing in May-July, while the other months exhibit an increasing trend. In general, the dry season (October to February of the following year) exhibits an apparent trend of increasing, which is more pronounced in Shilong station than Anxi station, particularly in winter (December to February of the following year). Comparing SPI value's changes in the drainage 
TABLE 2: Statistics of M-K for SSI and SPI on monthly time scales.

\begin{tabular}{lccccccccccccc}
\hline Time series & Jan & Feb & Mar & Apr & May & Jun & Jul & Aug & Sep & Oct & Nov & Dec & Total series \\
\hline SSI $_{\text {Shilong }}$ & $2.10^{\mathrm{b}}$ & $2.06^{\mathrm{b}}$ & 0.87 & 1.05 & -0.78 & $-2.60^{\mathrm{c}}$ & -0.74 & 1.13 & $1.82^{\mathrm{a}}$ & 0.89 & $1.85^{\mathrm{a}}$ & $2.38^{\mathrm{c}}$ & $3.23^{\mathrm{c}}$ \\
SSI $_{\text {Anxi }}$ & $1.84^{\mathrm{a}}$ & 1.58 & 1.05 & 1.54 & -1.02 & $-1.66^{\mathrm{a}}$ & -0.15 & 1.38 & $1.95^{\mathrm{a}}$ & 1.13 & 1.28 & $2.57^{\mathrm{c}}$ & $2.19^{\mathrm{b}}$ \\
SPI & 0.78 & 0.95 & 0.98 & 0.89 & -0.37 & -0.34 & 0.39 & 1.57 & 1.18 & -0.08 & 0.23 & 0.42 & $1.96^{\mathrm{b}}$ \\
\hline
\end{tabular}

Note: $a, b$, and c mean the trend reached significant level of $0.1,0.05$, and 0.01 , respectively.
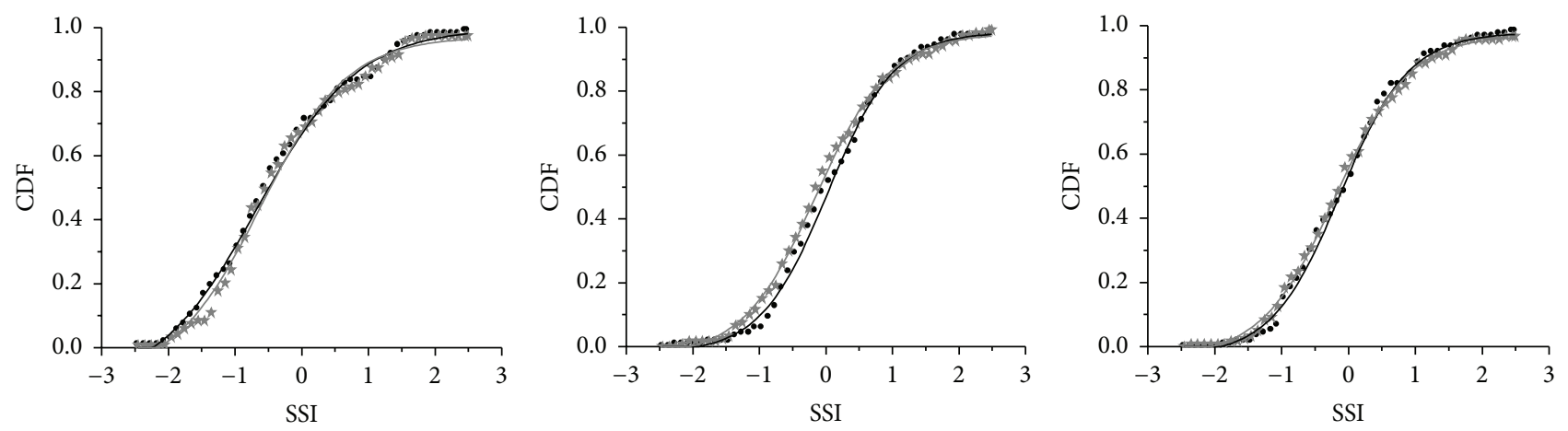

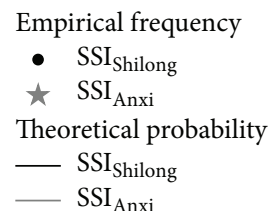

(a)

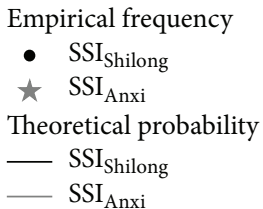

(b)
Empirical frequency
- $\mathrm{SSI}_{\text {Shilong }}$
$\star$ SSI $_{\text {Anxi }}$
Theoretical probability
- SSI $_{\text {Shilong }}$
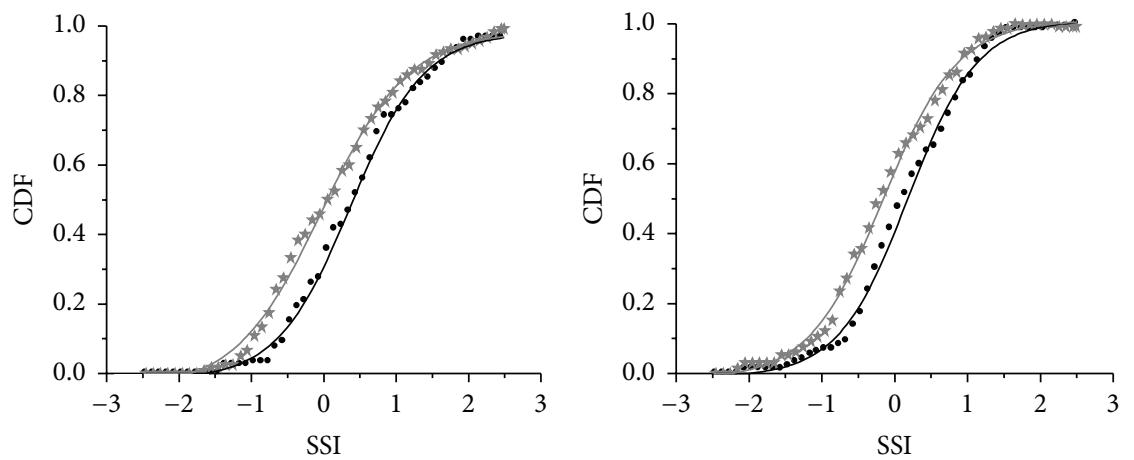

$$
\begin{aligned}
& \text { Empirical frequency } \\
& -\quad \mathrm{SSI}_{\text {Shilong }} \\
& \star \mathrm{SSI}_{\text {Anxi }} \\
& \text { Theoretical probability } \\
& -\mathrm{SSI}_{\text {Shilong }} \\
& \hline \mathrm{SSI}_{\text {Anxi }}
\end{aligned}
$$

(d)

$$
\begin{aligned}
& \text { Empirical frequency } \\
& \bullet \quad \mathrm{SSI}_{\text {Shilong }} \\
& \star \mathrm{SSI}_{\text {Anxi }} \\
& \text { Theoretical probability } \\
& -\mathrm{SSI}_{\text {Shilong }}
\end{aligned}
$$

(e)

FIGURE 2: Comparison of cumulative distribution frequency of SSI in different decades: (a) 1960-1969, (b) 1970-1979, (c) 1980-1989, (d) 1990-1999, and (e) 2000-2010.

basin, the evolution of SSI values at the two hydrological stations did not coincide with or correspond to SPI values. This result is particularly evident at Shilong station. Overall, the monthly SSI values in the Jinjiang River Basin have an apparent intra-annual variation characteristic.

4.1.2. Decadal Change Response. The cumulative distribution functions (CDFs) of SSI-1 at Shilong and Anxi stations for different decades (1960-1969, 1970-1979, 1980-1989, 19901999, and 2000-2010) were plotted, represented by 1960s, 1970s, 1980s, 1990s, and 2000-2010, respectively. The decadal evolution of hydrological drought frequency in the drainage basin was compared between two hydrological stations (Figure 2). All the CDFs passed K-S tests at chosen confidence level of $99 \%$. The frequency variation of hydrological drought for 1960s, 1970s, and 1980s at Anxi station is consistent with 


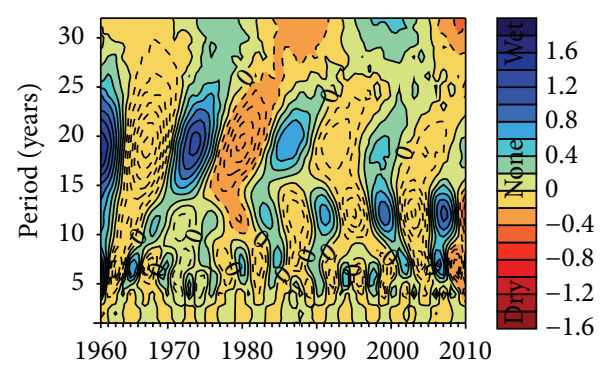

(a)
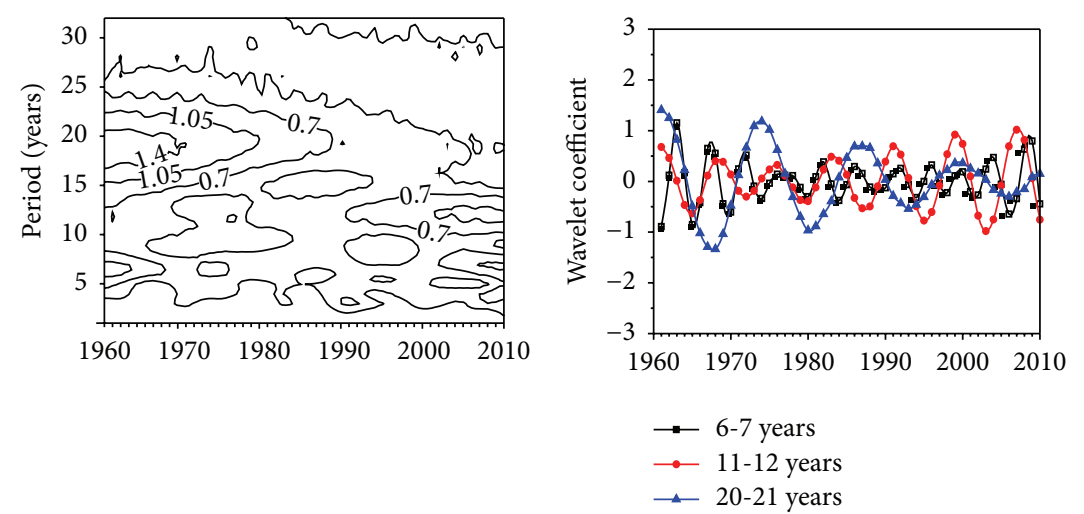

(c)

FIGURE 3: Annual SPI series of wavelet coefficients (a), annual SPI series of modulus square (b), and annual SPI series of wavelet coefficient of primary period.

Shilong station for the drainage basin by the distance between CDFs. In contrast, the variation between Shilong and Anxi station shows inconsistency after 1980s. In particular, the frequency of hydrological drought in the 1990s significantly decreased.

4.1.3. Response of Periodic Change. Morlet wavelet was used to conduct a periodic analysis of SPI series in the drainage basin on the annual scale. The real part of the wavelet transform coefficient, the modulus square time-frequency distribution, and the real part of the wavelet transform coefficient of the main period were obtained, as shown in Figure 3. For convenient analysis, the positive of the real part of the wavelet coefficient was characterized as a solid line to indicate that the SPI value at this stage is high (e.g., prone to wetness). In contrast, the negative of the real part of the wavelet coefficient was characterized as a dashed line to indicate that the SPI value at this stage is low (e.g., prone to drought).

From Figure 3(a) we can see that the annual scale of SPI time series includes many strong and weak periodic oscillations at different time scales that reflect the characteristics of alternating variation between wet and dry. The modulus square time-frequency distribution of wavelet coefficient (Figure 3(b)) shows that three apparent periodic oscillations exist, 6-7 years, 11-12 years, and 20-21 years for the annual SPI time series, among which the oscillation of the 20-21-year time scale is more significant than others but is weaker after 1980s. These results suggest good consistency with Minjiang River Basin, which is similar to the geographical features of the Jinjiang River Basin by using the EMD method [39].

Figure 3(c) shows SPI main periodic oscillations; the periodic oscillation of 20-21 years has been gradually weakened but the oscillation in 11-12 years has been gradually strengthened, suggesting that under global warming the occurrence or shifting of drought-flood in the drainage basin became more frequent. As a result, measures are necessary to prevent the risks of drought-flood and secondary disasters.

The calculation of the real part of wavelet transform coefficients for Shilong and Anxi stations at the same time scales shows that three apparent periodic oscillations existed around 6-7 years, 11-12 years, and 20-21 years for SSI series of the two hydrological stations. Figures 4(a), 4(b), and 4(c) show the comparison of the main period wavelet coefficient of SSI at two hydrological stations with SPI. The wavelet coefficient of SSI lags behind SPI, indicating the time lag between hydrological drought and meteorological drought. For the periodic oscillation around 6-7 years, the wavelet coefficient of the two hydrological stations keeps synchronous fluctuation with SPI in the drainage basin. The nonsynchronization was evident for the periodic oscillation around 11-12 years, particularly after 1980s. In contrast, the SSI of Anxi station remained almost synchronous with SPI for the periodic oscillation around 20-21 years, but the nonsynchronization for Shilong station was evident at the end of 1980s. To better explain the changes before and after 1980s about the main periodic oscillations, we analyzed the correlations between SPI and SSI wavelet transform coefficients for Shilong and Anxi station in different periods. From Table 3 we can clearly see that the correlations between SPI and SSI of main period wavelet coefficient at Shilong station are lower than at Anxi station, especially during 1980-2010. The higher correlation of SSI and SPI supports the greater synchronization between them.

4.2. Response Time of Hydrological Drought to Meteorological Drought at the Shilong Station. Previous studies have shown that SPI exhibits multiple time scale characteristics $[13,15,17$, 18]. An appropriate choice of SPI time scale can effectively indicate dry and wet conditions and also can indicate the response time of hydrological drought to meteorological drought [17-20]. The above analysis shows that the lack of synchronization between hydrological drought and meteorological drought at Shilong station became more evident after the 1980s. The dam and impoundment expansion project for Shanmei Reservoir was completed in 1982, and that year was taken as the breakpoint between the period with no reservoir effect (1960-1982) and the period with a reservoir effect (1983-2010). The relationships between monthly scales 

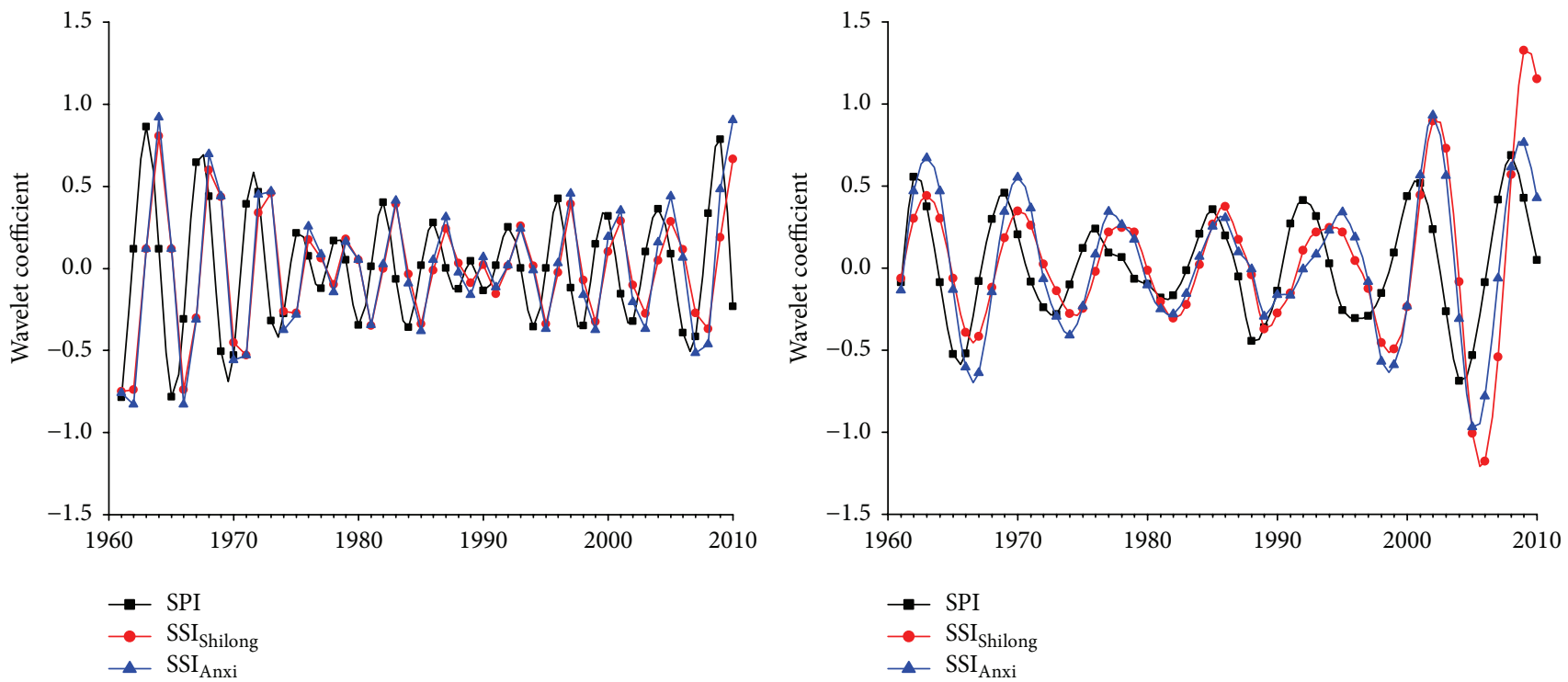

(a)

(b)

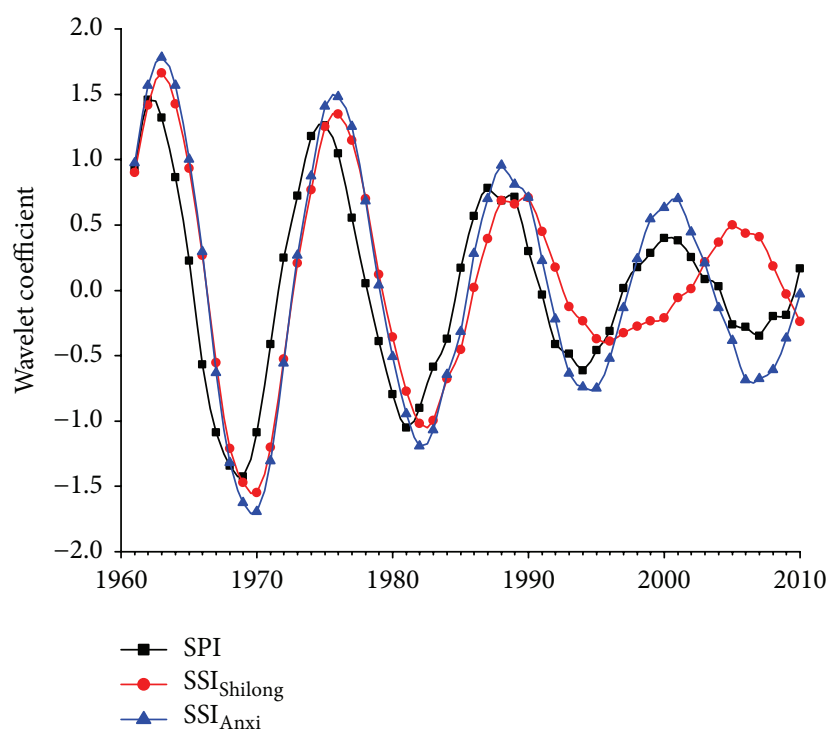

(c)

FIGURE 4: Comparison of main periodic oscillations change between SPI and SSI: (a) 6-7 years, (b) 11-12 years, and (c) 20-21 years.

TABLE 3: Correlations between SPI and SSI of main period wavelet coefficient in different periods.

\begin{tabular}{|c|c|c|c|c|c|c|}
\hline \multirow{2}{*}{ Period } & \multicolumn{3}{|c|}{ 1960-1979 } & \multicolumn{3}{|c|}{ 1980-2010 } \\
\hline & $6-7$ years & $11-12$ years & 20-21 years & 6-7 years & 11-12 years & $20-21$ years \\
\hline Shilong & 0.999 & 0.512 & 0.880 & 0.988 & 0.403 & 0.468 \\
\hline Anxi & 0.999 & 0.607 & 0.890 & 0.993 & 0.470 & 0.904 \\
\hline
\end{tabular}

SSI and SPI on different time scales (from SPI-1 to SPI-12) for the two periods (1960-1982 and 1983-2010) were analyzed at different months (from January to December). The results illustrate the degree of consistency of SSI and SPI at the time scale: greater PCC values are more consistent and indicate that this response time is more sensitive and vice versa. Overall, Figures 5(a) and 5(b) show that the response time of hydrological drought to meteorological drought exhibited seasonal characteristics. However, compared with the period with no reservoir effect, correlations between monthly scale SSI and short time scales SPI (e.g., SPI-1 and SPI-2) at each month become weaker, which indicates that the response time of hydrological drought to meteorological drought in the period with a reservoir effect at Shilong station becomes 


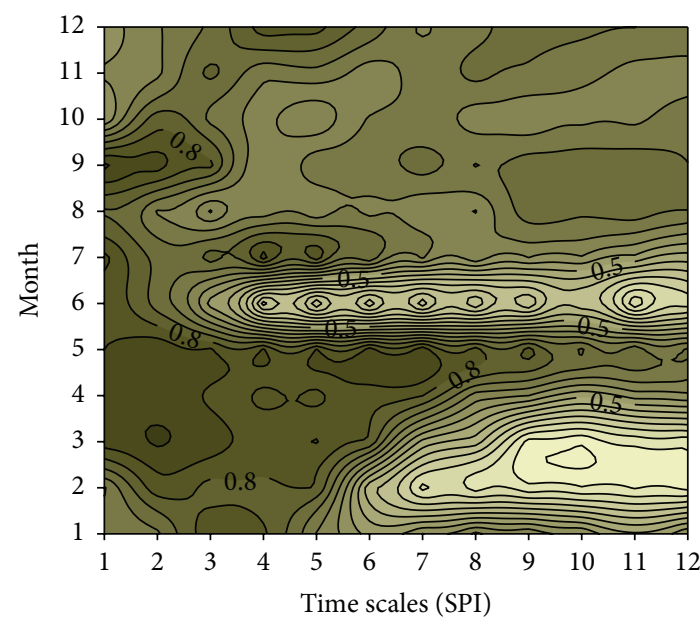

(a)
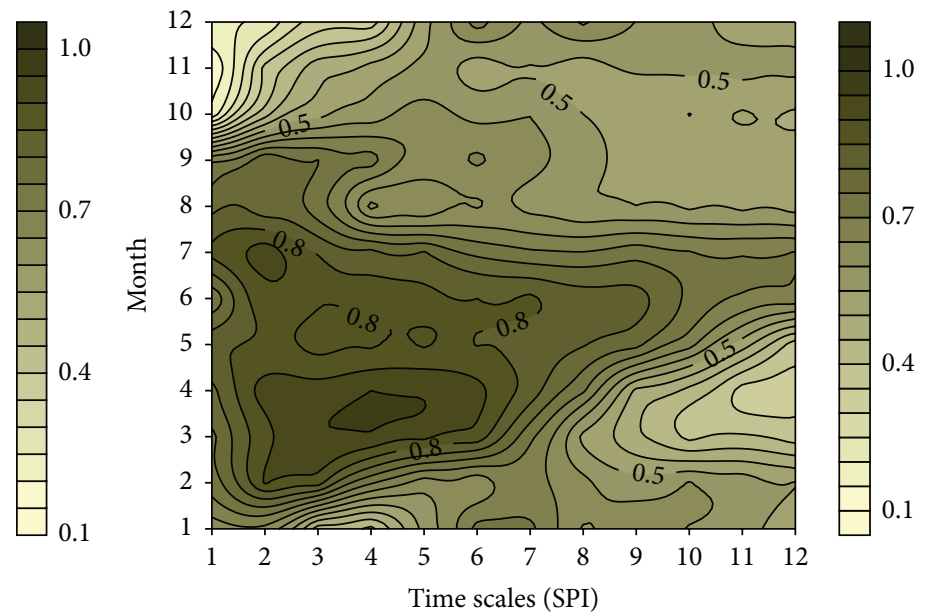

(b)

FIGURE 5: Monthly correlation coefficients between SSI-1 and SPI at different time scales (from SPI-1 to SPI-12) in Shilong hydrological station; (a) the period without reservoir effect (1960-1982); (b) the period with reservoir effect (1983-2010).

longer, in general. The response times in spring, summer, autumn, and winter have changed from 1-7, 1-2, 1-3, and 3-5 months to $2-7,1-3,1-4$, and 6-9 months, respectively.

The years with significant drought were further selected to verify the changes of the correlation between SSI and SPI for Shilong station under the regulation of the Shanmei Reservoir. Because this region is one of the regions with the most scarce water resources in Fujian Province, the drought in this drainage basin is close to the drought in the entire province [31]. Due to limited data in the basin, the years with severe drought throughout the entire province were selected for this analysis. According to the Fujian Provincial Bureau of Statistics [30] and related materials (http:// www.doc88.com/p-652201703763.html) over 340000 ha of land was affected by drought in 1950-1995; the recorded years with severe drought were 1963, 1971, 1977, 1983, 1986, 1991, 2003, and 2009. The monthly SPI and SSI of the above 8 years were extracted for analysis (due to the lag effect of hydrological drought to meteorological drought, advanced and delayed 6 months were extended for the severe drought year). As seen in Figure 6, the fluctuation of SSI corresponded to SPI in 1963, 1971, and 1977 before the 1980s. It exhibits an excellent correlation with an average Pearson coefficient of 0.82 (Table 3). However, for the years after the 1980s (i.e., 1983, $1987,1991,2003$, and 2009), the average lag time significantly increased. It is particularly obvious for the years 1987, 1991, and 2003. In addition, the correlation of SSI and SPI was poor compared with that before the 1980s, with an average Pearson coefficient of 0.66 (Table 4). It indicates that the function of regulation by Shanmei Reservoir affects the correlation between SSI and SPI, resulting in a change in the response time of hydrological drought to meteorological drought at Shilong hydrological station.

4.3. Discussion. Although the evolution of hydrological drought at two hydrological stations showed a similar decreasing trend (decreased droughts) and the hydrological drought was generally correlated with meteorological drought, M-K test results for SSI and SPI on a monthly scale showed that the evolution of hydrological drought in the drainage basin exhibited a nonsynchronized change with meteorological drought. This change is more evident at the Shilong station than the Anxi station; the $\mathrm{M}-\mathrm{K}$ values in Shilong hydrological station were significantly higher than at Anxi station for November to February but lower for June to July. The frequency variation of hydrological drought of each decade at Anxi station is almost synchronized with meteorological drought for the drainage basin, while Shilong station exhibited a different and nonsynchronized pattern. The periodic oscillation of Shilong station was almost consistent with the corresponding period of Anxi station as well as the drainage basin before the end of 1980s. However, the difference became significant on the 20-21-year cycle scale.

The SPI is based on precipitation deficits and therefore is purely dependent on climate anomalies [13, 42]. The evolution and periodic oscillation of hydrological drought at two hydrological stations (Shilong and Anxi station) in Jinjiang River Basin are consistent with meteorological drought in general, which indicates that climate change plays a role in the evolution of hydrological drought. Under a similar climate condition, the inconsistency of SSI series and SPI series at the corresponding time scale was more significant for Shilong station than Anxi station, which is strongly related to human activities (e.g., dam construction and operation). Overall, the human activities in the Jinjiang River Basin primarily included a change in land use and the construction of hydraulic projects. Lin et al. [43] investigated the land use data of the Jinjiang River Basin in 1985 and 2006 and applied the Soil and Water Assessment Tool (SWAT) model to simulate the response of flood-drought streamflow to land use changes. Their results showed that due to a decrease in woodlands and an increase in agricultural land, under the same precipitation 
TABLE 4: Correlations between SSI and SPI in typical severe drought years.

\begin{tabular}{lcccccrrr}
\hline Period & \multicolumn{2}{c}{ No reservoir effect (1960-1982) } & \multicolumn{4}{c}{ Reservoir effect (1983-2010) } \\
\hline Drought year & 1963 & 1971 & 1977 & 1983 & 1987 & 1991 & 2003 & 2009 \\
Pearson correlation & 0.862 & 0.834 & 0.778 & 0.831 & 0.568 & 0.784 & 0.716 & 0.395 \\
\hline
\end{tabular}

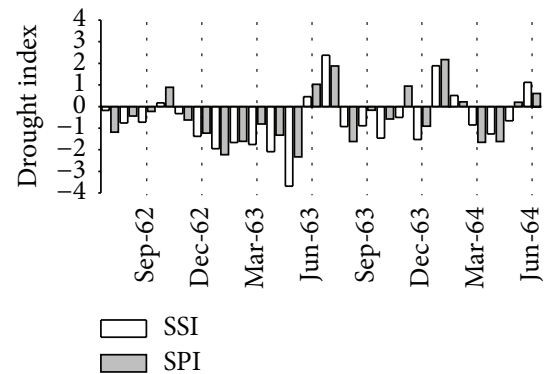

(a)

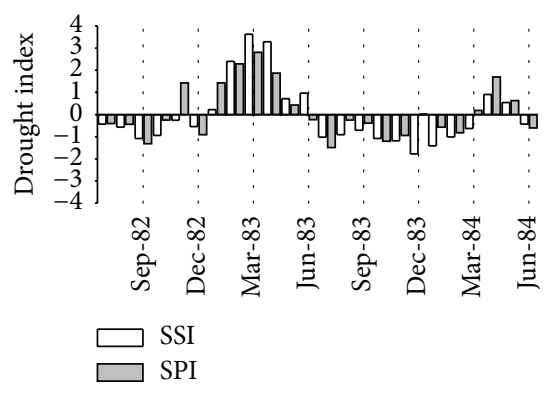

(d)

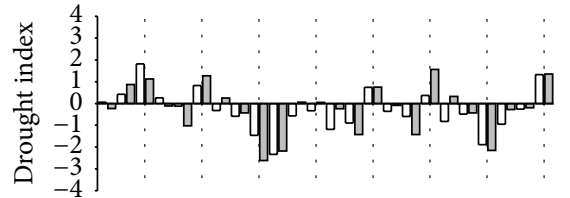

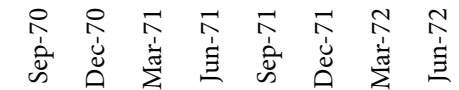

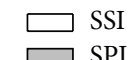

(b)

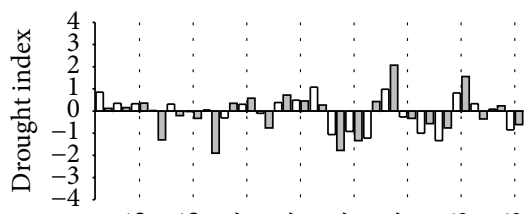

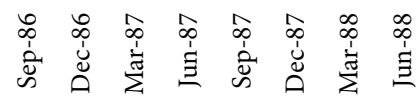

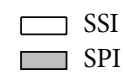

(e)

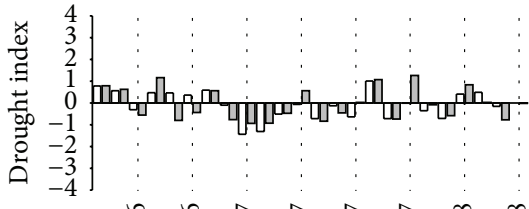

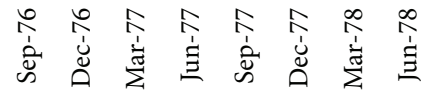

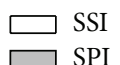

(c)

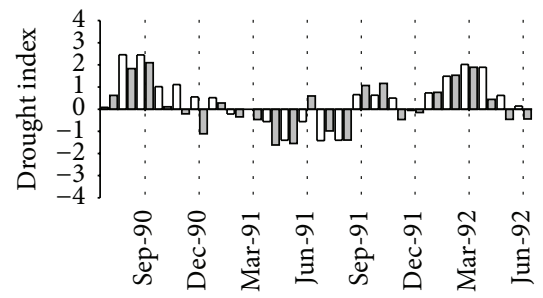

(f)

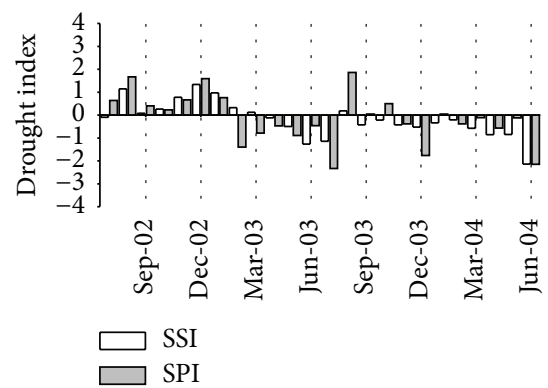

(g)

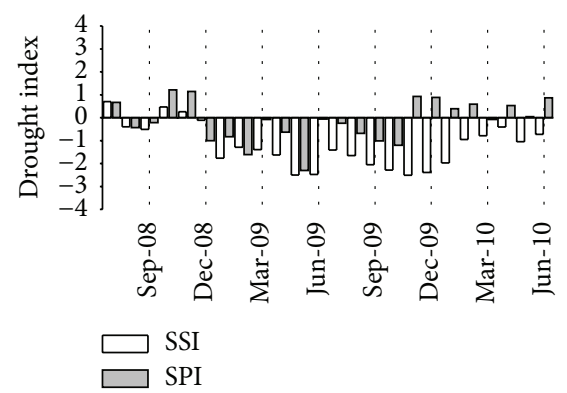

(h)

Figure 6: Typical drought years of monthly evolution: (a) 1963, (b) 1971, (c) 1977, (d) 1983, (e) 1987, (f) 1991, (g) 2003 , and (h) 2009.

conditions, no significant difference of the streamflow rate change was observed between the two stations. Therefore, the evolution of hydrological drought at Shilong station was caused by other human activities, such as the construction of large reservoirs. The completion of the Shanmei Reservoir with multiple-annual regulating functions, including the completion of dam protection and impoundment expansion projects in 1979-1982, has produced a significant impact on the interannual and particularly the intra-annual variations in streamflow of the downstream Shilong station. Meanwhile, the Longmentan Water Diversion Project, completed in 1989, introduced the streamflow from the Dazhangxi mainstream of the Min River to Huyangxi of upstream Dongxi of the Jinjiang River by transbasin diversion. This part of streamflow entered into the Shanmei Reservoir for unified regulation.
The direct result of these projects is the significant effect on the interannual increase and intra-annual stability of streamflow for Shilong station. Figure 7 shows the change trends of the coefficient of variation $(\mathrm{Cv})$ (Figure $7(\mathrm{a})$ ) and concentration (Cr) (Figure 7(b)) of the intra-annual streamflow for Shilong and Anxi stations, respectively. The intraannual streamflow change stabilized, and the decreasing trend was less affected by the reservoir than Anxi station.

\section{Conclusions}

In general, the evolution of hydrological drought was associated with meteorological drought at the two hydrological stations in the Jinjiang River Basin, and they both exhibited a decreasing trend. However, the hydrological drought 


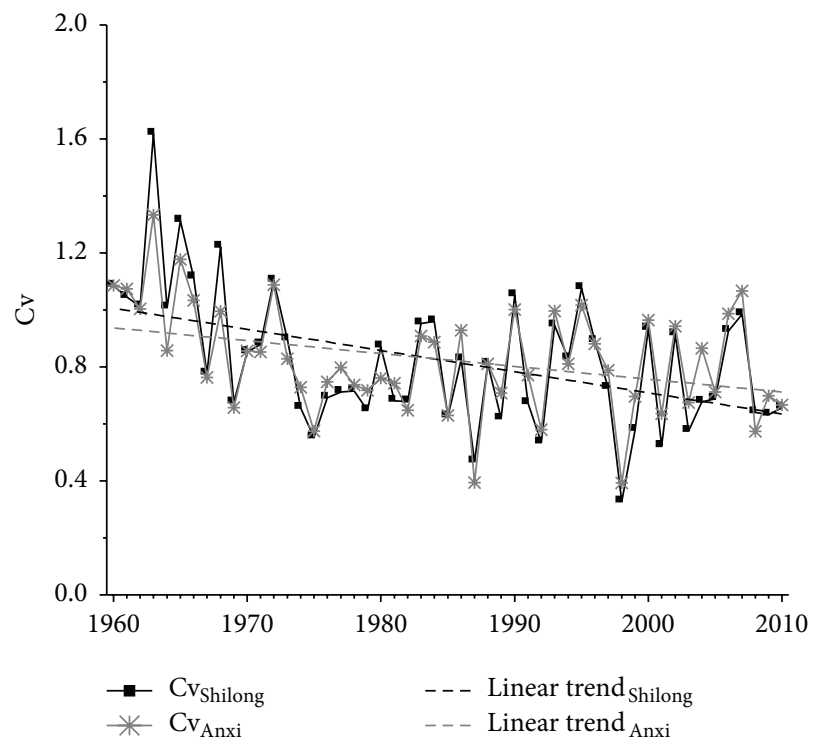

(a)

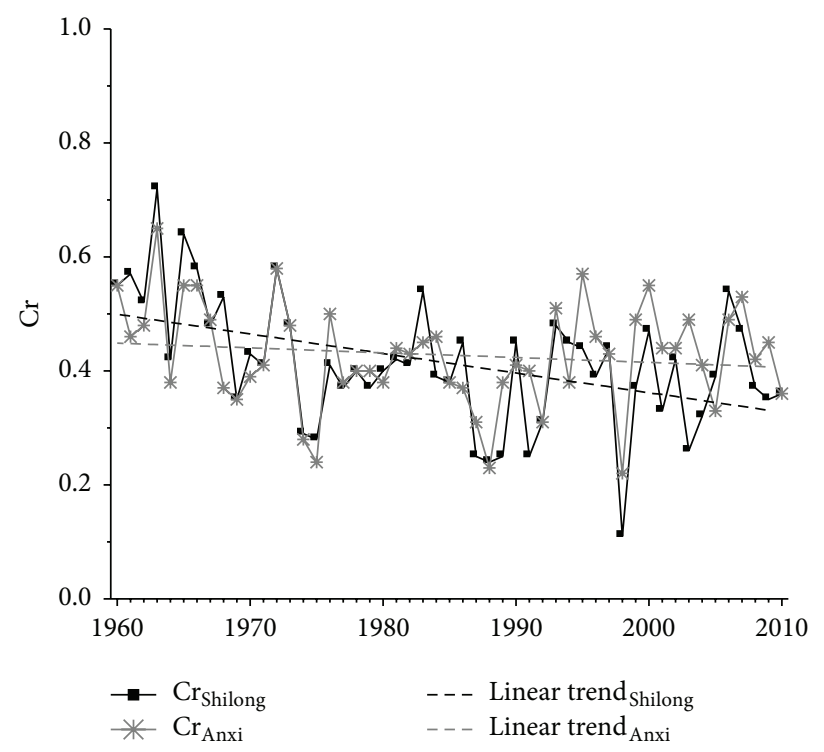

(b)

FIGURE 7: Interannual variation trend of streamflow in the Jinjiang River Basin.

decreased during November to February of the following year and increased during May to July, showing a nonsynchronized change with that of meteorological drought. This result was more evident at Shilong station than Anxi station. The primary reason is that an important human activity in the drainage basin, the multiple-annual regulation of Shanmei Reservoir, has significantly affected the runoff at Shilong station and correspondingly affected the evolution of hydrological drought.

Due to the impact of Shanmei Reservoir, the response time of hydrological drought to meteorological drought for Shilong station exhibited a changed seasonal variation (i.e., spring, summer, and autumn have extended 1 month on average, and winter has extended 3-4 months on average).

To a large extent, the regulation function of large reservoirs usually can change the temporal and spatial evolution of runoff and hydrological drought in the drainage basin. Therefore, further investigation of the response pattern of hydrological drought to meteorological drought under the impact of large reservoirs is crucial to the realization of early warning, drought prevention, and mitigation.

\section{Competing Interests}

The authors declare that there are no competing interests regarding the publication of this paper.

\section{Acknowledgments}

The study was supported by the Science and Technology Major Program of Fujian Province (Grant no. 2015Y4002) and the National Natural Science Foundation of China (Grant nos. 41301031 and 41501106). The hydrological data is provided by Fujian Provincial Hydrology and Water Resources
Survey Bureau, and the meteorological data is provided by the Fujian Provincial Meteorological Bureau. The authors wish to thank Greg Mierle for kind proofreading.

\section{References}

[1] IPCC, Managing the Risks of Extreme Events and Disasters to Advance Climate Change Adaptation: Special Resport of the Intergovernmental Panel on Climate Change, Cambridge University Press, New York, NY, USA, 2012.

[2] V. Mishra and K. A. Cherkauer, "Retrospective droughts in the crop growing season: implications to corn and soybean yield in the Midwestern United States," Agricultural and Forest Meteorology, vol. 150, no. 7-8, pp. 1030-1045, 2010.

[3] N. Carroll, P. Frijters, and M. A. Shields, "Quantifying the costs of drought: new evidence from life satisfaction data," Journal of Population Economics, vol. 22, no. 2, pp. 445-461, 2009.

[4] A. Dai, K. E. Trenberth, and T. Qian, "A global dataset of Palmer Drought Severity Index for 1870-2002: relationship with soil moisture and effects of surface warming," Journal of Hydrometeorology, vol. 5, no. 6, pp. 1117-1130, 2004.

[5] G. Leng, Q. Tang, and S. Rayburg, "Climate change impacts on meteorological, agricultural and hydrological droughts in China," Global and Planetary Change, vol. 126, pp. 23-34, 2015.

[6] H. Jia and D. Pan, "Drought risk assessment in yunnan province of China based on wavelet analysis," Advances in Meteorology, vol. 2016, Article ID 1579415, 10 pages, 2016.

[7] World Meteorological Organization, "Drought monitoring and warning: concepts, progress and future challenges," WMO Publication 1006, 2006.

[8] American Meteorological Society, "Meteorological droughtpolicy statement," Bulletin of American Meteorological Society, vol. 78, pp. 847-849, 1997.

[9] H. Geng and B. Shen, "Definition and significance of hydrological droughts," Agricultural Research in the Arid Areas, vol. 10, no. 4, pp. 91-94, 1992. 
[10] A. F. Van Loon and G. Laaha, "Hydrological drought severity explained by climate and catchment characteristics," Journal of Hydrology, vol. 526, pp. 3-14, 2015.

[11] T. P. Barnett, D. W. Pierce, H. G. Hidalgo et al., "Human-induced changes in the hydrology of the western United States," Science, vol. 319, no. 5866, pp. 1080-1083, 2008.

[12] Z. Xing, D. Yan, L. Fan et al., "Advances in the study of anthropogenic effects on the drought and flood events," Journal of Natural Resources, vol. 28, no. 6, pp. 1070-1082, 2013.

[13] B. T. Mckee, J. Nolan, and J. Kleist, "The relationship of drought frequency and duration to time scales," in Proceedings of the 8th Conference on Applied Climatology, pp. 179-184, American Meteorological Society, Anaheim, Calif, USA, January 1993.

[14] R. R. Heim Jr., "A review of twentieth-century drought indices used in the United States," Bulletin of the American Meteorological Society, vol. 83, no. 8, pp. 1149-1165, 2002.

[15] P. Angelidis, F. Maris, N. Kotsovinos, and V. Hrissanthou, "Computation of drought index SPI with alternative distribution functions," Water Resources Management, vol. 26, no. 9, pp. 2453-2473, 2012.

[16] T. Raziei, J. Daryabari, I. Bordi, and L. S. Pereira, "Spatial patterns and temporal trends of precipitation in Iran," Theoretical and Applied Climatology, vol. 115, no. 3-4, pp. 531-540, 2014.

[17] D. C. Edossa, M. S. Babel, and A. D. Gupta, "Drought analysis in the Awash River Basin, Ethiopia," Water Resources Management, vol. 24, no. 7, pp. 1441-1460, 2010.

[18] Y. Wang, X. Chen, Y. Chen, M. Liu, and L. Gao, "Flood/drought event identification using an effective indicator based on the correlations between multiple time scales of the Standardized Precipitation Index and river discharge," Theoretical and Applied Climatology, 2015.

[19] A. F. Van Loon, M. H. J. Van Huijgevoort, and H. A. J. Van Lanen, "Evaluation of drought propagation in an ensemble mean of large-scale hydrological models," Hydrology and Earth System Sciences, vol. 16, no. 11, pp. 4057-4078, 2012.

[20] J. Niu, J. Chen, and L. Sun, "Exploration of drought evolution using numerical simulations over the Xijiang (West River) basin in South China," Journal of Hydrology, vol. 526, pp. 68-77, 2015.

[21] J. Y. Shin, M. Ajmal, J. Yoo, and T.-W. Kim, "A Bayesian network-based probabilistic framework for drought forecasting and outlook," Advances in Meteorology, vol. 2016, Article ID 9472605, 10 pages, 2016.

[22] S. Shukla and A. W. Wood, "Use of a standardized runoff index for characterizing hydrologic drought," Geophysical Research Letters, vol. 35, no. 2, pp. 41-46, 2008.

[23] L. Wen, K. Rogers, J. Ling, and N. Saintilan, "The impacts of river regulation and water diversion on the hydrological drought characteristics in the Lower Murrumbidgee River, Australia," Journal of Hydrology, vol. 405, no. 3-4, pp. 382-391, 2011.

[24] F. A. M. Al-Faraj and M. Scholz, "Assessment of temporal hydrologic anomalies coupled with drought impact for a transboundary river flow regime: the Diyala watershed case study," Journal of Hydrology, vol. 517, pp. 64-73, 2014.

[25] Q. Huang, Z. Sun, C. Opp, T. Lotz, J. Jiang, and X. Lai, "Hydrological drought at dongting lake: its detection, characterization, and challenges associated with three gorges dam in central Yangtze, China," Water Resources Management, vol. 28, no. 15, pp. 5377-5388, 2014.

[26] B. Zhang, C. He, M. Burnham et al., "Evaluating the coupling effects of climate aridity and vegetation restoration on soil erosion over the Loess Plateau in China," The Science of the Total Environment, vol. 539, pp. 436-449, 2016.

[27] H. B. Mann, "Nonparametric tests against trend," Econometrica, vol. 13, pp. 245-259, 1945.

[28] M. G. Kendall, Rank Correlation Measures, Charles Griffin, London, UK, 1976.

[29] W. Wang, J. Ding, and Y. Li, Hydrology Wavelet Analysis, Chemical Industry Press, Beijing, China, 2005.

[30] S. Lu and Y. Wang, The Climate of Fujian, Beijing Meteorological Press, 2012.

[31] W. Pan, J. Chen, H. Chen, C.-G. Zhang, and L.-C. Li, "Dynamic monitoring of drought in Fujian Province from MODIS remote sensing data," Chinese Journal of Eco-Agriculture, vol. 16, no. 4, pp. 1015-1019, 2008.

[32] I. M. Chakravarti, R. G. Laha, and J. Roy, "Handbook of methods of applied statistics," Technometrics, vol. 10, no. 4, pp. 872-873, 1968.

[33] A. Melesse, W. Abtew, T. Dessalegne, and X. Wang, "Low and high flow analyses and wavelet application for characterization of the Blue Nile River system," Hydrological Processes, vol. 24, no. 3, pp. 241-252, 2010.

[34] L. Guo, Z. Xia, H. Zhou et al., "Hydrological changes of the lli river in Kazakhstan and the possible causes," Journal of Hydrologic Engineering, vol. 20, no. 11, Article ID 05015006, 2015.

[35] H. Zhang, Q. Huang, Q. Zhang, L. Gu, K. Chen, and Q. $\mathrm{Yu}$, "Changes in the long-term hydrological regimes and the impacts of human activities in the main Wei River, China," Hydrological Sciences Journal, vol. 61, no. 6, pp. 1054-1068, 2016.

[36] C. Antoniak, "Extended X-ray absorption fine structure of bimetallic nanoparticles," Beilstein Journal of Nanotechnology, vol. 2, no. 1, pp. 237-251, 2011.

[37] R. Da Silva, L. C. Lamb, and M. C. Barbosa, "Universality, correlations, and rankings in the Brazilian universities national admission examinations," Physica A: Statistical Mechanics and Its Applications, vol. 457, pp. 295-306, 2016.

[38] L. Zhao, J. Wu, and J. Fang, "Robust response of Streamflow drought to different timescales of meteorological drought in Xiangjiang river basin of China," Advances in Meteorology, vol. 2016, Article ID 1634787, 8 pages, 2016.

[39] Y. Chen and X.-W. Chen, "Evolution of spatio-temporal characteristics of flood and drought in Fujian Province for recent 50 years: an SPI-based analysis," Journal of Natural Disasters, vol. 20, no. 3, pp. 57-63, 2011.

[40] K. Yang, B. Chen, J. Chen et al., "Characteristic of climate change in Fujian province," Chinese Agricultural Science Bulletin, vol. 27, no. 8, pp. 302-309, 2011.

[41] B. Wu, The Characteristics of the 50-Year Climate Variability in Fujian Province, Nanjing University of Information Science and Technology, Nanjing, China, 2005.

[42] Y. Wang, J. Li, P. Feng, and F. Chen, "Effects of large-scale climate patterns and human activities on hydrological drought: a case study in the Luanhe River basin, China," Natural Hazards, vol. 76, no. 3, pp. 1687-1710, 2015.

[43] B. Lin, X. Chen, H. Yao et al., "Analyses of landuse change impacts on catchment runoff using different time indicators based on SWAT model," Ecological Indicators, vol. 58, pp. 5563, 2015. 

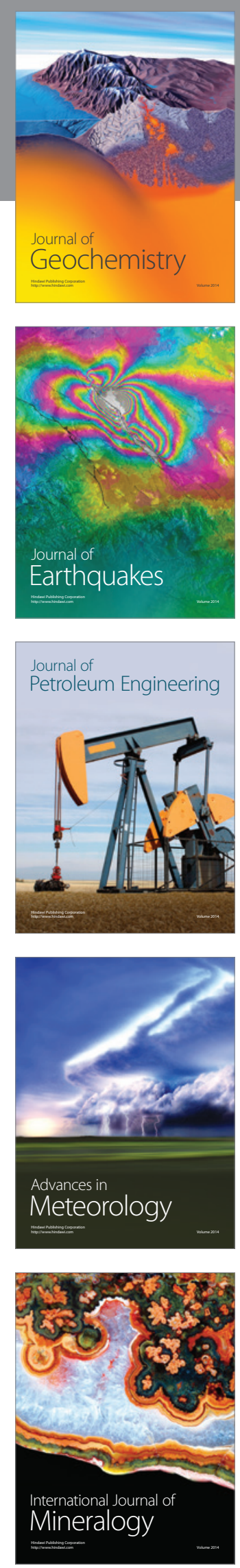
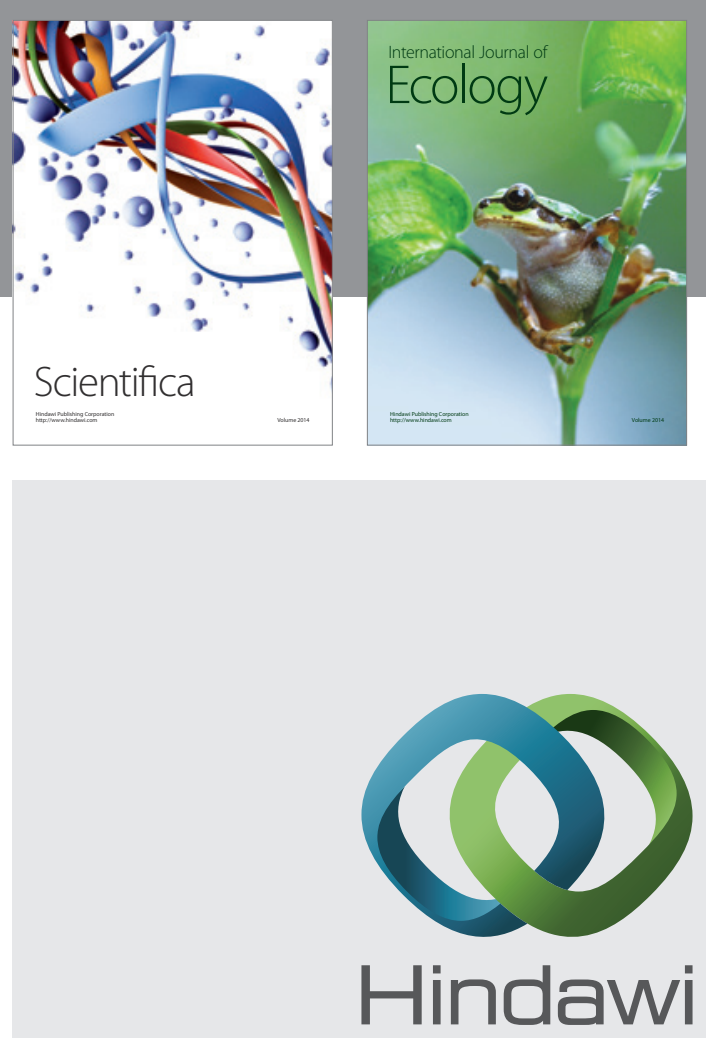

Submit your manuscripts at

http://www.hindawi.com
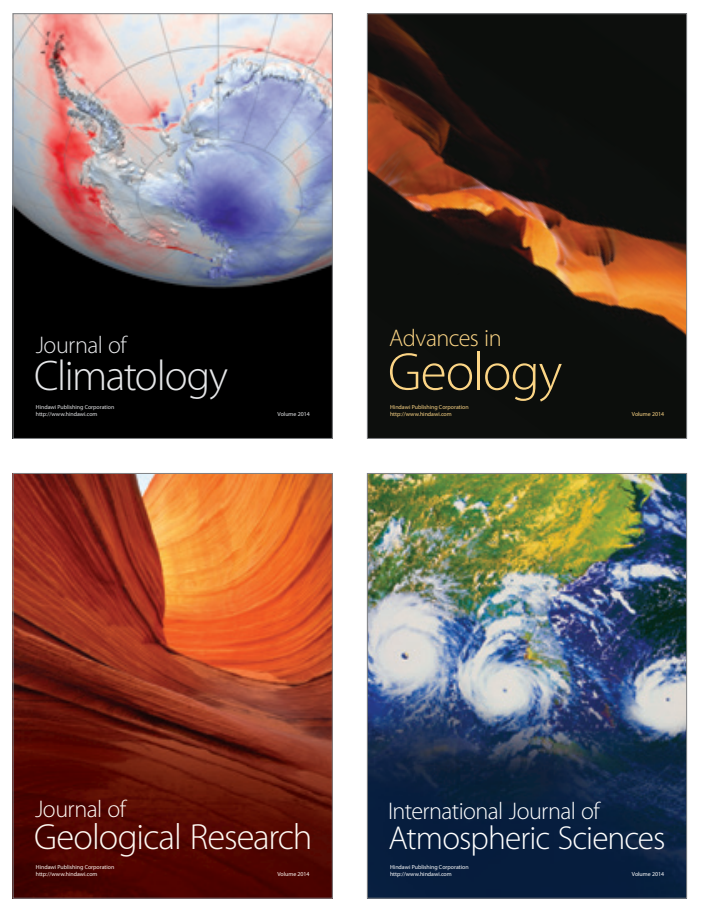

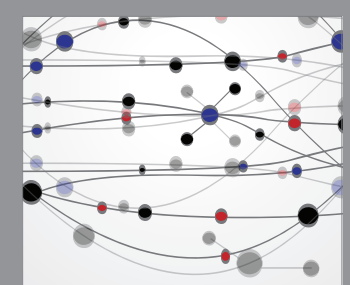

The Scientific

\section{World Journal}
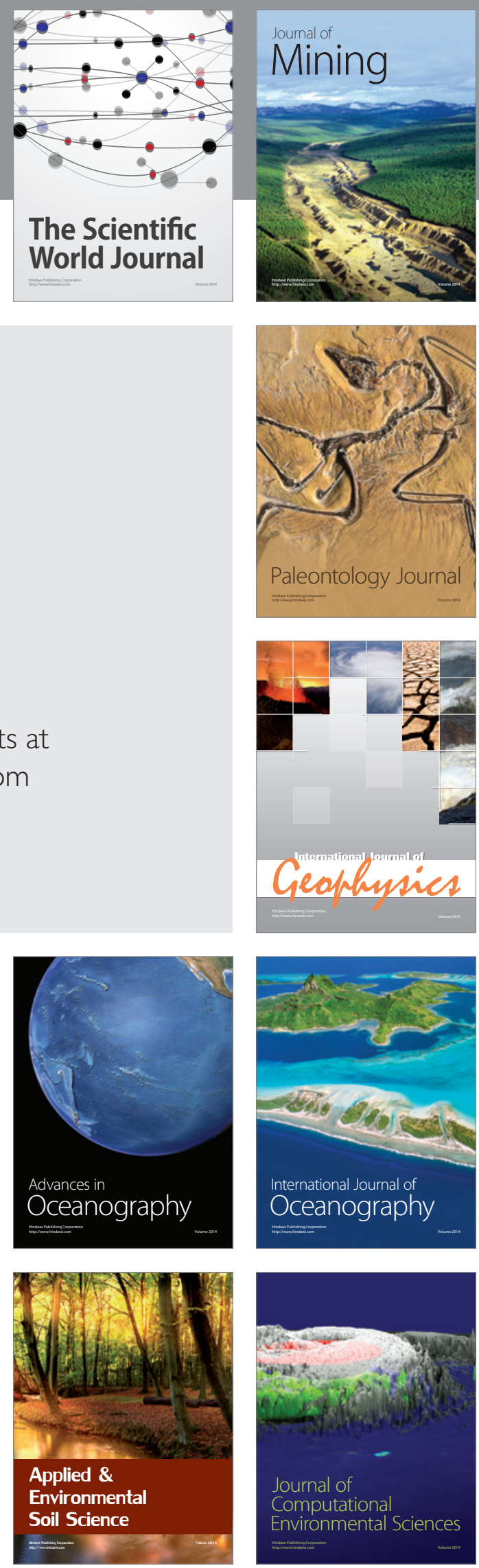